\title{
PAIXÃO, SUBVERSÃO E RASURA HISTÓRICA NO ROMANCE NO PAÍS DAS SOMBRAS (1979), DE AGUINALDO SILVA
}

\author{
Tiago Calarans Simões* \\ Sandra Maria Pereira do Sacramento ${ }^{* *}$
}

RESUMO: Nossa proposta visa a promover rasuras ao caráter heteronormativo da historiografia tradicional, utilizando o romance No país das sombras (1979), do escritor pernambucano Aguinaldo Silva. Aqui, lançamos olhares que reflitam acerca do ato ficcional, com desfecho (trágico) devido a um relacionamento amoroso entre dois soldados "del-rey", condenados por conspiração contra a Coroa portuguesa. Buscamos identificar como o escritor traça paralelos entre esse caso ocorrido em Pernambuco, no século XVII, e a repressão sexual e política durante a ditadura hétero-civil-militar no Brasil (1964-1988). No romance em destaque, analisamos como ocorre a articulação entre as representações não aceitas pela moral vigente, tanto no passado mais remoto, quanto nos acontecimentos do século XX; cujas pulsões envolvem uma paixão fora do paradigma heteronormativo e conspiração política, quando entram em cena narrativas fundantes da construção da masculinidade, amparadas no militarismo, em defesa da pretensa moralidade da família brasileira. Dessa maneira, convocamos ao palco de nossa análise literária a identificação de fissuras aos mitos do passado, cujas sombras ainda se encontram projetadas no cenário nacional contemporâneo. Delineamos, no romance, a presença de um agenciamento, que se materializa por meio do ato subversivo da personagem Tália (uma cortesã), na articulação entre luxúria e solidariedade, colocando em evidência o questionamento de certa concepção de natureza (entendida como conjunto de regras "divinas" e inflexíveis: um produto acabado), ao encarnar personificação da natureza como "força” (processo não acabado, gerando possibilidades), tal como ocorre na paixão entre Antônio Bentes de Oliveira e Pedro Ramalho de Sá.

PALAVRAS-CHAVE: Gênero; Heteronormatividade; Solidariedade.

\footnotetext{
* Mestrando em Letras da Universidade Estadual de Santa Cruz (Uesc).

** Doutora em Letras pela Universidade Federal do Rio de Janeiro (UFRJ). Professor Pleno da Universidade Estadual de Santa Cruz (Uesc).
} 
- Padre, já lhe ocorreu que o sistema de vida inventado por nós na Europa não tenha aqui a menor utilidade? É um mundo novo, como o senhor di₹: Por que não aceitar o fato de que é possível comeşar, aqui, exatamente do nada?

Tália, a cortesã. (SILVA, 1979, p. 50-51).

Aguinaldo Silva é um conhecido dramaturgo, escritor, roteirista jornalista e cineasta brasileiro. Entretanto, a profissão que o consagra nacionalmente é a de telenovelista da Rede Globo, que o torna popularmente conhecido por diferentes gerações e classes sociais, uma personalidade que está nas mídias de massa. Mas, poucos conhecem Aguinaldo Silva como escritor de extensa (e subversiva) narrativa literária produzida no período da ditadura civil-militar (1965-1988). Boa parte de seus textos são classificados por Malcolm Silverman, em Protesto e o novo romance brasileiro (2000), como "romance problema", "romance jornalístico" e "romance realista-político". É fato que essa e outras “etiquetas literárias" trazem análises críticas pertinentes. No entanto, no nosso exercício crítico, procuramos seguir o conselho do historiador Carlo Ginzburg de "[...] reconduzir ao conhecimento histórico não mais fenômenos aparentemente atemporais, mas fenômenos aparentemente negligenciáveis” (GINZBURG, 1989, p. 10); ou seja, os rastros e sinais que nos permitem construir outras facetas (pouco revisitadas, mas bastante produtivas) de Aguinaldo Silva. Esse romancista, à época da resistência, escreveu $A$ república dos assassinos (1976) e foi jornalista, entre outros, do jornal homossexual1 de oposição ao regime, "O lampião da Esquina”, que circulou entre 1978 e 1981. Não pretendemos aqui negar ou afirmar um ou outro lado (o subversivo do passado / ou o "conformado" do presente) do autor: as migalhas de pão nas trilhas da história existem para serem investigadas e os fragmentos de um todo (apenas idealizado) apresentam diferentes facetas do ser humano.

\footnotetext{
${ }^{1}$ Utilizamos o termo homossexual para delimitar o jornal, pois, "Homossexualidades, era o termo muito utilizado até o começo dos anos 1990 para se referir ao conjunto de orientações sexuais e identidades de gênero consideradas não normativas ou dissidentes" (QUINALHA, 2017, p. 15). Muitas identidades que hoje se encontram na sigla LGBT e suas derivações, foram tratadas de forma genérica e homogeneizadora por "homossexualidades": travestis, gays afeminados, gays masculinos e lésbicas eram entendidas como pessoas homossexuais. Dessa forma, trata-se de uma terminologia ainda válida, quando contextualizamos as pesquisas com sujeitos não atendidos pela heteronormatividade, como é o caso em nosso recorte.
} 
Ao "[...] supor como potencialmente mais rica a documentação mais improvável" (GINZBURG, 2007, p. 277), analisamos o romance, da editora Civilização Brasileira, No país das sombras (SILVA, 1979), em sua potencialidade sensual, homoerótica, política e crítica ao rasurar visões moralistas de nossa colonização religiosa e estabelecer redes de sentido que leiam a "tragédia" do passado como precursora das "farsas" autoritárias do presente, utilizando a metáfora marxiana (MARX, 2011). Daqui em diante, ao nos referirmos ao romance No país das sombras, para evitar a repetitividade, quando citarmos, colocaremos apenas a referência da página (p.).

O texto a caça aos homossexuais e travestis na ditadura militar (2015) nos faz refletir sobre o fato de a História ser uma narrativa, um meio de interpretar o passado e, como diria Donna Haraway (1995), uma tecnologia de olhar, um saber localizado através dos corpos que importam em determinado contexto. Nessa perspectiva, o saber histórico único das narrativas oficiais está em constante disputa com outras versões, que denunciam poderes e discursos autoritários, que silenciaram o passado cruel (1964-1985) da ditadura civil-militar brasileira e as vozes daquelas e daqueles que amargaram nos seus porões brutos e sangrentos. As pessoas LGBTQI+2 ${ }^{2}$ não escaparam desta realidade de violência, assassinato e silenciamento no contexto ditatorial. Os textos Ditadura e homossexualidades: repressão, resistência e a busca da verdade, organizado por James Green e Renan Quinalha (2015); O relatório da comissão nacional da verdade (2014) e a tese de doutorado Contra a moral e os bons costumes: a politica sexual da ditadura brasileira (1964-1988), do professor Renan Honório Quinalha, nos

\footnotetext{
${ }^{2}$ Esta sigla guarda-chuva engloba lésbicas, gays, pessoas transgêneras; pessoas queer, que se identificam com a orientação sexual/gênero não enquadradas em definições binárias; as pessoas intersexo são aquelas que não nascem com a anatomia sexual e/ou reprodutiva, antes chamadas de hermafroditas; Já o + é uma forma de mostrar a perspectiva solidária e coletiva do movimento ao incluir também pessoas que não têm interesse em atividades sexuais, a pessoa assexual; pessoas pansexuais, que sentem atração por qualquer identidade de gênero, bem como os aliados, que são as pessoas parceiras da comunidade LGBTQI+ e visam construir uma sociedade equânime para essas pessoas. A opção por grafar a sigla em letras coloridas se dá por conta da pesquisa "Sociedade monocromática, identidades coloridas", desenvolvida por Renato Gonçalves Peruzzo no Programa de Pós-Graduação em Letras: Linguagens e Representações, na qual o pesquisador defende que a normatização perpassa a linguagem e suas convenções, também acadêmicas, como a escolha da fonte monocromática, marcadamente heteronormativa.
} 
dão um bom panorama da questão. É fato que o Brasil é o país que mais mata LGBTQI+ no mundo, diante da crescente onda de preconceito, fundamentalismo e fascismo, julgamos urgente reforçar e somar esforços à linha de raciocínio e pesquisa proposta abaixo:

\begin{abstract}
Aos poucos, a história começa a nos contar nomes de mulheres, um trabalho árduo de pesquisadoras e feministas que olham novamente para aquele período e se perguntam: Onde estavam as mulheres? Assim surgiram nomes [...] vitais na luta contra o Regime Militar de 64: Amélia Teles, Ana Maria Aratangy, Crimeia de Almeida, Nildes Alencar, Maria Aparecida Contin, entre outras. Mulheres que foram invisibilizadas pelos relatos hegemônicos. (masculinos) do período, mas que têm surgido como nomes importantes na luta pela redemocratização do país. O saber histórico, ou seja, das narrativas, está em constante disputa. Precisa ser visto e revisto o tempo todo. No caso específico das pessoas transexuais, travestis, gays e lésbicas, é preciso um esforço na releitura do período da Ditadura civil-militar para encontrarmos nossa participação. Tanto as violações que sofremos, quanto nossa participação nas lutas, como foi o caso de Herbert Daniel, do Colina. (Comando de Libertação Nacional), organização à qual também pertenceu Dilma Rousseff, nossa atual Presidenta. (VIEIRA, 2015, não paginada)
\end{abstract}

Seguindo a proposta de Vieira (2015), é importante dar visibilidade não apenas autores, obras, sujeitos e fatos que localizem a violência sofrida por "homossexuais" durante a "ditadura hétero-militar" (QUINALHA, 2017); mas, também o papel ativo dessa população na resistência e luta contra o regime moralista, analisando, no âmbito literário, representações questionadoras dos estereótipos que retratavam os homossexuais como criminosos, doentes e degenerados, que atentavam contra a "natureza". Para realizar essa proposta, vamos visibilizar a produção pouco trabalhada do autor Aguinaldo Silva e sua participação política, jornalística e autoral nessa época como agente histórico em plena militância estética e política, bem como por sua capacidade, nessa e em outras obras, de tematizar o autoritarismo e a resistência de pessoas marginalizadas, personagens femininas e LGBTQI+.

Embora práticas e ideias, que são englobadas no termo "homofobia", possam ser identificadas em nosso país, muito antes da ditadura militar, os estudos da Comissão Nacional da Verdade (CNV), constataram que, 
[...] durante a ditadura civil-militar, de forma mais intensa do que em outros períodos da nossa história, o autoritarismo de Estado também se valeu de uma ideologia da intolerância materializada na perseguição e tentativa de controle de grupos sociais tidos como uma ameaça ou perigo social. A criação da figura de um 'inimigo interno' valeu-se de contornos não apenas políticos de acordo com a Doutrina da Segurança Nacional, mas também morais, ao associar a homossexualidade a uma forma de degeneração e de corrupção da juventude. (QUINALHA, 2017, p. 25)

Para nós, isso indica que, em análises interessadas em questões de gênero e sexualidade, o termo ditadura "hétero-militar" é bastante pertinente, pois tem como pressuposto que os importantes (e necessários) estudos críticos que cunharam a perspectiva histórica e social, presumida no termo ditadura "civil-militar", não deram a devida importância e atenção para as pessoas homossexuais (LGBTQI+), necessidade que nos leva ao uso do termo hétero-civil-militar. Diante disso, neste trabalho, visamos somar esforço na iniciativa de resgatar esses fatos e sujeitos históricos, bem como sua perspectiva e ponto de vista em relação ao regime, na figura de Aguinaldo Silva, com temas, personagens e fatos representados em No país das sombras.

A narrativa foi escrita durante a ditadura civil-militar (década de 1960). Trata-se de um narrador, que exerce o jornalismo e investiga como dois soldados se tornaram amantes, em Pernambuco do século XVII, sendo acusados de conspiração contra o rei de Portugal e, posteriormente, condenados à forca. Esse amor foi manipulado pela Coroa e pela Igreja Católica para forjar uma suposta conspiração que desencadeou uma sequência de perseguições e condenações, como forma de coibir o aparecimento de movimentos contrários a Portugal. Segundo o poder colonial, os insurretos visavam à “[...] criação de um Estado separatista no qual seriam devidamente liquidados todos aqueles que se mostrassem fiéis à coroa" (p. 71). É importante situar que o texto abordado foi publicado em 1979, pondo em narrativa ficcional o passado colonial do Brasil, tendo como enredo aquelas figuras marginalizadas: cortesãs, soldados, bárbaros - esses condenados por degredo - que seriam os primeiros fundadores de nossa identidade nacional: 
Havia uma loucura qualquer se espalhando naquela terra recém-descoberta, eram as raízes de alguma coisa que talvez pudesse ser achada depois [...] aquela estranha gente que eu fora descobrindo a cortesã Tália, o general-provedor, os bárbaros e degredados, [...] teriam sido o que hoje se chama de "as origens da nacionalidade"? Não, eu me recusava a acreditar.. (p. 70)

Dessa forma, o autor vai construindo a hipótese - negando a imagem colocada pela moral do regime militar - de que essas figuras "degeneradas" e "pervertidas" seriam tipos novos a questionar a "natureza biológica" do ser humano. Não é necessário, para nosso recorte, a análise de documentos e fatos da inquisição que perseguiu homossexuais no Brasil colonial, mas é importante pontuar que textos como: Devassos no paraíso: a homossexualidade no Brasil - da colônia à atualidade, de João Silvério Trevisan (2018), Trópico dos pecados: moral, sexualidade e Inquisição no Brasil, de Ronaldo Vainfas (2010), e Relações Raciais entre Homossexuais no Brasil Colonial, de Luiz Mott (1992), podem trazer luz à discussão.

O romance No país das sombras relata: "Em agosto de 1604, dois homens foram condenados à morte pela justiça do rei, nos tribunais de Olinda" (p. 18). Essa é a afirmação que levará o narrador-personagem (que deseja ver seu trabalho transformado em obra e financiado pelo Instituto Nacional do Livro) à sua incansável investigação pelos documentos históricos acerca do caso, como os autos da condenação, e os escritos de personagens centrais da trama: da cortesã Tália e do padre Barruel, bem como das confissões dos soldados apaixonados, Antônio Bentes de Oliveira e Pedro Ramalho de Sá, como na "confissão" do segundo:

Pedro Ramalho de Sá surgiu diante de mim meia hora depois do prazo marcado. E sem uma palavra, como se um estranho demônio nos impulsionasse, nos aproximamos um do outro, nos tocamos e ali, mesmo, em meio à noite, num jogo que não sabemos sequer como terminou, nos entregamos a toda espécie de intimidades. Tenho certeza de que, no pequeno espaço de tempo que durou toda aquela eternidade, fomos donos um do outro, nos completamos.. (p. 21)

Como percebemos na citação acima, a narrativa se desenvolve sem linearidade temporal, está entre o presente, do qual o narrador é personagem (que não é nomeada durante 
a narrativa, mas há várias semelhanças com o autor do livro). A apresentação dos “textos históricos" investigados pela personagem é apresentada ao leitor com suposições e divagações do protagonista, quando se propõe a preencher com sua imaginação o que os vazios dos documentos históricos não dão conta. O personagem, no Brasil da década de 1960, se encontra num contexto de repressões policiais ao movimento estudantil, de fuga de amigos e artistas para o exílio, pressionado pela angústia de vê-los fugindo ou presos sem poder se envolver mais, o que o leva a questionar sua pouca ação nos fatos. Em um diálogo, com um amigo, líder estudantil, acerca da sua pesquisa do passado colonial, seu interlocutor parece concluir que o trabalho caminha por fazer "uma analogia com o que se passa atualmente" (p. 31), o que é negado pelo protagonista: "faço questão de dizer que em nenhum momento foi essa a minha intenção. Sempre achei que a história se basta a si mesma, não é honesto que nós, pesquisadores, tentemos encaminhá-la em direção às nossas idéias" (p. 31). Esses posicionamentos reflexivos sobre o fazer histórico e literário, sobre ficção e realidade, aparecem em outros momentos do livro, como nas citações da epígrafe e da nota (elementos pré-textuais da obra analisada), nas quais o autor afirma que as personagens são seres de ficção: “A ação é, por vezes, roubada à realidade, mas acaba por ter uma solução imaginária. Qualquer semelhança entre a literatura e a história é acidental” (p. 9). Para nós, pelo contrário, acreditamos que essas semelhanças são necessárias, por apresentarem uma visão crítica, capaz de trazer rasuras aos relatos majoritários que, por exemplo, ajudaram a construir a imagem do Brasil como um país pacífico, com mulheres, que endossaram a cultura machista, sem a presença de homossexuais ou dissidentes políticos. Ao contrário, a História não mostra as personalidades silenciadas; enquanto a literatura surge como maneira de dar visibilidade à alteridade, com possibilidade de participação e agenciamento. As justificativas do autor, de seu material ser estritamente ficcional e não histórico, estão de acordo com uma época muito austera, na qual havia a necessidade de deixar claro que se tratava de ficção, para não correr o risco de ser barrado pela censura, ao tentar falsear "a História”. Essa História com $\mathrm{H}$ maiúsculo, única, oficial, higienizada e moralizadora, que 
despolitiz̧a (ação de esvaziar a força e potência política de algo) as presenças dos chamados abjetos, ${ }^{3}$ colocando-os (sempre) às margens do saber e desprovidos de sua dignidade.

Embora, desde a introdução, apareça uma espécie de distanciamento do autor-pessoa em relação à História, o que ocorre no texto é bem diferente: a narrativa pode ser vista como produto de uma estratégia de releitura, conforme descrita por Bonnici (2003), que empreende um movimento descolonizador da visão moralista católica da coroa Portuguesa, consequentemente traçando paralelos entre esta do passado e a do presente do regime militar. A narrativa nos leva à reflexão de que o processo de condenação que combatia sensualidade, homossexualidade e luxúria, aliando-as à conspiração política, foi fruto de "correlação de forças" e de uma "rede de poderes" sempre presente na História do Ocidente, da articulação entre os poderosos e a religião: "Nas relações de poder, a sexualidade não é o elemento mais rígido, mas um dos dotados da maior instrumentalidade: utilizável no maior número de manobras e podendo servir de ponto de apoio, de articulação às mais variadas estratégias" (FOUCAULT, 2017, p. 112). Dessa maneira, esse uso estratégico da sexualidade (como subversão moral, natural e política) é manipulado nos dois momentos históricos, pela Coroa portuguesa, Igreja e depois pela ditadura militar: "desse encontro abençoado entre a Igreja e a Ordem, talvez o primeiro, e a partir do qual, nesse abençoado país em que vivemos, elas seguiram sempre juntas” (p. 92). É, nessa trama, que identificamos que "A transgressão, e não o acomodamento, eis a ideologia inicial deste "país das sombras' e futuro país do carnaval, a qual já principiava então a ser duramente reprimida pelas armas e pela religião" (vide: orelha do livro) e essas imagens são sempre correlacionadas no decorrer da trama.

\footnotetext{
${ }^{3}$ Sobre a ideia de "abjeto", a filósofa Judith Butler (em entrevista) fornece exemplo didático de como a mídia ocidental põe em cena a morte de refugiados libaneses e turcos: são corpos e vidas ausentes de sua matéria, não ganham as mesmas histórias complexas de europeus que morreram ou cometeram crimes. Dessa forma, “[...] recebemos uma produção diferenciada, ou uma materialização diferenciada, do humano. E também recebemos, acho eu, uma produção do abjeto. Então, não é que o impensável, que aquilo que não pode ser vivido ou compreendido não tenha uma vida discursiva; ele certamente a tem. Mas ele vive dentro do discurso como a figura absolutamente não questionada, a figura indistinta e sem conteúdo de algo que ainda não se tornou real" (PRINS; MEIJER, 2002, p. 162).
} 
Esse poder colonial teme a figura de Tália, que é um "Elemento de suma importância na narrativa, por ser a primeira a adivinhar o caráter subversivo da luxúria (termo usado de modo depreciativo pelo padre Barruel de Lajenest, em discussão com Tália), e a identificar paixão e conspiração como elementos inseparáveis e igualmente corrosivos" (vide: orelha do livro) já que, prostitutas, homossexuais e soldados insatisfeitos reuniam-se na casa de Tália e a cortesã é colocada sob suspeita como uma possível "protetora” desses elementos: "sua casa é praticamente o único divertimento de que dispõe a tropa [...] a pretexto de que ali vão com o objetivo puro e simples da esbórnia” (p. 67). Essa insubordinação se personificaria com o cunho político dado à condenação acerca do relacionamento entre os soldados - o alvo da investigação do protagonista do romance - revelada como produto forjado pela aliança entre o padre e o Capitão-Geral (aliança entre Igreja e Estado), que definiria "o apoio da igreja à história que, em relação ao crime dos amantes, deveria prevalecer" (p. 91). Os fatos, que se seguiram às condenações, são cuidadosamente ficcionalizados e, em grande medida, têm forte relação de semelhança com o que aconteceu no Brasil, no século XX, após a promulgação do AI-5 (Ato Institucional no $n^{\circ}$ ); fase em que houve forte coerção, por parte do regime militar, instituído em 1964:

"Em nome da lei e da ordem" - escreveu Padre Barruel de Lajenest nos últimos dias que viveu em sua cidade constantemente ameaçada pela floresta -, "e para proteção da Santa Madre Igreja", fora preciso mentir. No mesmo dia em que os motivos oficiais do crime dos dois soldados se tornaram públicos, houve perseguições e mortes. Algumas casas acabaram incendiadas, bens foram sequestrados e outras pessoas igualmente submetidas a julgamentos sumários. Muitas fugiram para o interior da floresta, e lá aderiram a uma clandestinidade que não durou muito - o ambiente adverso os perdeu, e eles morreram de fome, ou foram devorados por feras. E o que prevaleceu foi a mentira que ele ajudara a institucionalizar. (p. 93)

$\mathrm{Na}$ tentativa de restabelecer "todos os elos da história", por meio de um enredo fictício, "relacionando-o de maneira extremamente original com o Brasil das passeatas, da repressão e da ilegalidade constitucional" (vide: orelha do livro), chega-se ao contexto real, 
isto é, à História: “a polícia a perseguir estudantes com cassetetes e bombas de gás lacrimogêneo no Brasil dos anos 60, em plena avenida Rio Branco, frente à mesma biblioteca em que se 'inventa' a estória” (cf. orelha do livro).

O romance analisado promove uma rasura, ao evidenciar uma colonização feita por padres, prostitutas, degredados e homossexuais e, em contrapartida, acaba por expor, alegoricamente, o presente vivido no Brasil, durante a ditadura hétero-civil-militar, isto é, que homossexualidade e liberação sexual caminhavam juntas com comunismo e reivindicação política. Em dupla associação, entre os fatos dos séculos XVII e XX, podemos dizer que ambos se aproximam quando, em No país das sombras (SILVA, 1979), o narrador se detém na confissão forjada de Antônio Bentes de Oliveira, feita pelo padre Barruel de Lajenest: “Após nossos encontros e as muitas vezes em que nossos corpos se enlaçaram passamos a ver que a vida fora feita para muito mais: cabe ao homem gritar suas razões e defendê-las [...] Nossos encontros passaram do amor febril à condução febril das nossas idéias” (p. 94). O texto questiona as "ficções" que serviram de base para o discurso do regime autoritário: a pretensa moralidade da família brasileira e a harmonia do governo militar, que, segundo Élio Gaspari, em Os documentos da censura,

[...] era precisamente a versão [do governo]: um país com um regime do qual não se desgostava, onde não há dissidentes, onde vige uma política habitacional equânime e um mercado de capitais onde as fortunas se multiplicam, sem homossexuais, sem comunistas e com algumas pequenas questões que só são exaltadas por aqueles que agem contra a ordem. (GASPARI, 1978, p. 1)

Na mesma linha argumentativa de Élio Gaspari, a ficção de Aguinaldo Silva localiza a gestação do gérmen e, ao mesmo tempo, o elo entre ordem e subversão, discurso recorrente na agenda do governo hétero-militar, em 1964. Com a chegada de nossos colonizadores, a ordem, representada pelo Estado colonial e Igreja, imiscuiu-se com a desordem e, ao mesmo tempo, necessita desta para a sua manutenção. Isto ocorreu entre portugueses, ligados à coroa imperial, com degredados e criminosos, os chamados cidadãos de "segunda classe". Outra discussão cara a ser observada em nossa análise do romance é a disputa política pelo conceito de natureza. Aqui, partimos do ponto de vista que as noções que 
nossa sociedade tem sobre natureza são socialmente construídas. Elas materializaram sua força de expressão em séculos de história e se reafirmam em atos performativos (assim como faz o gênero, na descrição de Butler), que se repetem no dia a dia, visando à sua pertinência discursiva:

\begin{abstract}
Assim, em que sentidos o gênero é um ato? Como em outros dramas sociais rituais, a ação do gênero requer uma performance repetida. Essa repetição é a um só tempo reencenação e nova experiência de um conjunto de significados já estabelecidos socialmente; e também é a forma mundana e ritualizada de sua legitimação. (BUTLER, 2003, p. 200)
\end{abstract}

De modo análogo à Judith Butler de que a pragmática discursiva, em ondas reiterativas, é que constrói o mundo, Luísa Severo Buarque de Holanda, no artigo Da mímesis antiga à imitação dos antigos (2008), afirma que, na transformação da noção de "natureza" grega para a latina, acabou-se conformando um sentido mais próximo daquelas concepções presentes nas sociedades ocidentais contemporâneas, a ideia de algo pronto e acabado:

A própria compreensão desse modelo se transformou, partindo da noção grega de physis - que constituía um processo não estanque de geração de substâncias, ou ainda, uma incessante geração de causas e efeitos - para a noção latina de natura como um produto acabado, uma obra física, cujos aspectos exteriores podiam ser reproduzidos pela habilidade artística humana. (HOLANDA, 2008, p. 136, grifo nosso)

É importante trazer essa visão mais flexível, presente na cultura grega, sobre a ideia de natureza, já que esse conceito vem à tona sempre que se fala de sexualidade, gênero e identidade por parte de discursos políticos e religiosos conservadores, patriarcais e elitistas. Essa visão de natureza como coisa pronta e acabada é discutida por Roland Barthes, em Mitologias (2009), através da noção de “mito" e a discussão do mesmo como uma "fala política":

O que o mundo fornece ao mito é um real histórico, definido, por mais longe que se recue no tempo, pela maneira como os homens o produziram ou utilizaram; e o que o mito restitui é uma imagem 
natural desse real. [...] o mito é constituído pela eliminação da qualidade histórica das coisas; nele, as coisas perdem a lembrança da sua produção. $\mathrm{O}$ mundo penetra na linguagem como uma relação dialética de atividades e atos humanos; sai do mito como um quadro harmonioso de essências. Uma prestidigitação inverteu o real, esvaziouo de história e encheu-o de natureza, retirou às coisas o seu sentido humano, de modo a fazê-las significar uma insignificância humana. (BARTHES, 2009, p. 234)

A ideia de natureza tida como algo "deixado por Deus", que representa um movimento que esvazia (e despolitiza, tirando o sentido histórico, temporal e local) a construção social e cultural humana na linguagem, é questionada pela fala de Tália (a cortesã), em uma bela e poética ação afirmativa que questiona séculos de tradição: “- Para mim, padre, eles não passavam de dois amantes" (p. 51). Em sua argumentação, a prostituta desautoriza a visão de natureza como fixa e inalterável. Questionada pelo padre “- [...] você considera o fato de dois homens se amarem uma coisa natural?" (p. 51), sobre "[...] o comportamento considerado segundo a moral de todas as épocas 'atos contra a natureza”' (p. 69), Tália responde: “- A natureza, para mim, é uma força em constante expansão, padre. Ela se permite a tudo" (p. 51). Instada por permitir o encontro entre os dois amantes "foi você quem deu guarida a estes dois soldados, quem permitiu que eles conspirassem abertamente" (p. 50), acaba sendo acusada de promover a "subversão" contra a "natureza moldada por Deus". Entretanto, esse amor "impossível” leva os dois apaixonados a matarem o General-Provedor, único meio encontrado de darem continuidade àquela relação homoerótica. Dessa forma, a luxúria e a conspiração política se materializam, na figura de uma mulher degredada, a cortesã, que, embora sendo portuguesa, não podia participar do círculo das "senhoras" cristãs, mas constitui uma peça fundamental na trama, ao articular luxúria e subversão. Por ser uma mulher, acaba "investida primeiramente pelo dispositivo de sexualidade, uma das primeiras a ser "sexualizada", é nela "onde sempre deveria figurar um valor" (FOUCAULT, 2017, p. 131), de preocupação com "o espaço familiar (do qual deve ser elemento substancial e funcional) e com a vida das crianças (que produz e deve garantir, por meio de uma responsabilidade biológico-moral que dura todo o período da educação): 
a mãe, com sua imagem em negativo que é a "mulher nervosa" (FOUCAULT, 2017, p. 113).

Aquela, que desfruta do prazer sexual, sem o vínculo com a maternidade, como Tália, logo é identificada, pelo padre, como a que permitiu e incentivou o ato subversivo. Trata-se, portanto, dessa "mulher nervosa" e "histérica", fora da ordem, que contraria o projeto da sexualidade domada e disciplinada, ocultada e negada, principalmente, no caso feminino, pelo cristianismo. Uma mulher sem homem, sem lei e sem falo, que comanda orgias em sua casa, dando guarida às reuniões de soldados, que se coloca não apenas como objeto de desejo, mas também que sente prazer, constitui um grande perigo: "Por trás da parede de palha, tocando-me com os dedos, eu me sentia feliz e privilegiada por testemunhar o modo como se amavam" (p. 53); e o risco, cada vez mais provável, de uma insurreição contra a Coroa portuguesa, que colocava aqueles soldados em situação de precariedade e abandono.

Essas representações - colocadas de forma consciente pelo escritor - efetivam, poética e politicamente, forças constantes, que se tornaram (aos olhos do regime) ameaças à instabilidade dos frágeis valores morais e políticos da elite do nosso país, tanto durante o regime hétero-civil-militar quanto no período atual da nossa cansada democracia: a sexualidade irruptiva da nossa juventude (que transborda em letras de funk, rap, sertanejo, arrocha e pagode), as lutas por autonomia do corpo feminino (como as lutas feministas pelo direito ao aborto), as LGBs (lésbicas, gays e bissexuais) na defesa da sua orientação sexual, as T's (trans e travestis), intersexuais, da identificação de gênero e toda uma série de sujeitos não inclusos nos projetos humanistas, modernos e globalizantes. Essas presenças continuam a gritar, seus corpos continuam a pulsar, sua tomada de consciência se espalha pela internet e pelas ruas, reivindicando, através de passeatas, por exemplo, acesso ao mercado de trabalho, ao ensino superior e à garantia de representação no sistema político. Essas subjetividades, corpos, sujeitos e coletivos, cada vez mais, têm buscado políticas de aliança e coalizão com outros grupos excluídos, rompendo com a ideia de que suas necessidades sejam 
vistas apenas como questões identitárias ou que devam estar simplesmente alijadas de uma luta política e econômica, na qual figuram em segundo plano.

Diferente da afirmação de Francis Fukuyama (1992)4 , não acreditamos que a história acabou, ao contrário, ela continua em processo e os acadêmicos têm grande papel em sua disseminação crítica. Essa ideia é defendida pela historiadora Joan Wallach Scott (2018), na entrevista ao Jornal Público (Portugal), na qual reflete sobre o importante papel que os acadêmicos têm em mediar um debate com estudantes do Ensino Básico, que não necessariamente se tornarão acadêmicos, e com a sociedade de um modo geral. Reconhecendo a distância entre o nosso trabalho "complexo" diante de "actores políticos e os media [que ainda] operarem com binários simplistas enquanto nós os tentamos desconstruir" (SCOTT, 2018, p. 1). Desta sorte, nós, acadêmicos, temos um papel importante de ação, pois:

Podemos intervir em diálogos públicos, explicar o nosso trabalho em fóruns públicos e nas redes sociais. Nós escrevemos para enriquecer e aprofundar visões políticas que promovam a igualdade e a justiça social e para auxiliar movimentos políticos que se dediquem a essas causas. (SCOTT, 2018, p. 1)

Seguindo esse raciocínio, compreendemos que a literatura deva ser utilizada como mais uma forma de intervenção, capaz de efetivar materialidade política às nossas utopias; elemento motivador de agência, ela pode, se utilizada de forma crítica, propiciar autorrepresentações afirmativas em seus leitores, enquanto sujeitos históricos, agentes sociais e políticos. Os pensadores Karl Marx e Friedrich Engels costumavam munir seus escritos políticos, filosóficos e econômicos de análises da ação ideológica da "superestrutura" na literatura (como constatado por Gyorgy Lukács ([1968]2010), em Marxismo e teoria da literatura, na parte I: "Marx e Engels, historiadores da literatura”), criticando autores e produzindo metáforas relevantes para o entendimento da divisão de classe, da decadência ideológica, da concentração de renda na sociedade e do dinheiro em seu valor de inversão (de

\footnotetext{
${ }^{4}$ No livro O Fim da História e o Último Homem, Fukuyama (1992) afirmou que o fim da união soviética e a propagação da cultura do consumo em escala mundial marcaram a vitória do mundo capitalista. Dessa forma, a procura de um modelo moderno de sociedade teria chegado ao fim, demarcando, nessa compreensão, "o fim da história".
} 
valores morais humanos), tal como o faz em Manuscritos econômicos filosóficos (MARX, [1930] 2004), ao tecer uma crítica literária moral de valores humanos comparando Goethe (Fausto) e Shakespeare (Timão de Atenas): "Shakespeare descreve acertadamente a essência do dinheiro para entendê-lo, comecemos primeiramente com a interpretação da passagem goethiana” (MARX, [1930] 2004, p. 159), tirando conclusões como: “Com a valorização do mundo das coisas aumenta em proporção direta a desvalorização do mundo dos homens." (MARX, [1844] 2004, p. 80); na parte I, do Manifesto comunista (1848). Valendo-se, às vezes, de metáforas poéticas para reforçar sua linha de pensamento: “Tudo o que era sólido e estável se desmancha no ar, tudo o que era sagrado é profanado e os homens [e mulheres, adição minha] são obrigados finalmente a encarar sem ilusões a sua posição social e as suas relações com os outros homens [e mulheres]" (ENGELS, MARX, 1998, p. 43); ao avaliar as disputas com a tradição/geração passada, em O 18 de Brumário de Luís Bonaparte (1852): "A tradição de todas as gerações passadas é como um pesadelo que comprime o cérebro dos vivos” (MARX, [1852] 2011, p. 25). Fosse por meio da crítica ao status quo defendido pelo "socialismo reacionário feudal": "Para atrair o povo a aristocracia desfraldou como bandeira a sacola do mendigo; mas assim que o povo acorreu percebeu que as costas da bandeira estavam ornadas com os velhos brasões feudais [...]"(ENGELS, MARX, 1998, p. 60), fosse na defesa da utopia de "dias melhores" (uma sociedade sem classes, socialistacomunista), era na análise literária, que os teóricos socialistas (Marx e Engels) erigiam sua crítica à manifestação da ideologia dominante, condenando ou concordando com obras e autores que estavam mais ou menos perto de ideais de "libertação" da "classe trabalhadora" e da crítica à sociedade estabelecida. A literatura pode e deve nos servir como força motora da política. Através de suas imagens, representações e experimentações, a leitura literária, observada nas possibilidades de denúncia não apenas do seu contexto de produção, mas também na irradiação da visão crítica a problemas que persistem no tempo - o que exige, no presente, a necessidade de resgate, dessas obras "esquecidas" (como acontece com a narrativa aqui analisada), "perdidas nos sebos" e em bibliotecas empoeiradas, por parte da crítica -, podem potencializar (junto com as nossas vivências, andanças, exílios e migrações) 
a força dos nossos olhares críticos. Nosso trabalho com a literatura também deve ser o de desfamiliarizar e estranhar a aparente normalidade de todas as formas de desigualdades sociais, que transformaram fatos históricos (do acúmulo de capital à LGBTfobia) em mitos naturais, que desdenham de qualquer possibilidade de mudança e alteração do comodismo, provocando desesperança, medo e desarticulação. A literatura deve desvendar, desmascarar e desmistificar o irracionalismo e a naturalização da aceitabilidade da miséria, da fome, da abjeção e dos preconceitos contra sujeitos de orientação sexual e identidades de gênero diversas.

Acreditamos que o comportamento de Tália, por meio de uma metáfora por nós lida em No país das sombras, - e [...] as metáforas são coisas sérias. Afetam a prática (HALL, 2018, p. 229) -, ativam uma importante postura ética do tipo de solidariedade que é importante ser desenvolvida para uma ação política de valorização da diferença que leve ao fortalecimento de redes e articulações dos grupos sociais em luta por políticas públicas, dignidade e superação das desigualdades sociais e econômicas. Para estabelecermos os valores de convivência social não apenas na igualdade, mas na diferença, é preciso não apenas o respeito e a convivência, mas também o cuidado com o outro: é necessário cuidarmos uns dos outros, estreitando os laços e elos, na busca por uma cidadania afetiva que caminhe para posturas de agenciamento efetivo. A imagem do acolhimento de Tália para com o amor entre os dois soldados, pode ser remetida a uma representação muito recorrente sobre as travestis prostitutas na bibliografia sobre o tema: a imagem da travesti puta, mais velha e experiente, que acolhe os jovens garotos gays que foram expulsos de casa por conta de sua feminilidade. Ela se faz a protetora da relação homoerótica - há na trama, um jogo de interações interseccionais no quesito da exclusão, já que os soldados são estranhados pelos outros pares por serem amantes, já Tália possui um status social que, embora seja metropolitano, é diferenciado do das senhoras portuguesas já que ela é uma cortesã e não uma "mulher de família" - e se solidariza com aqueles dois seres humanos, acompanha o nascer dessa paixão, permite que ela aconteça em sua casa, protegendo-os, mesmo quando o desfecho dessa união já não se encontra mais sob seu domínio, quando o destino dos 
amantes já está selado pela Igreja Católica e pelo Estado, ela caminha junto com eles (em luto), até o doloroso momento de sua execução pública:

Eu os amava também, eu os queria, eu desejava que ficassem ali para sempre, a salvo. [...] Eu decidira usar o mais negro de todos os meus vestidos - este seria o sinal mais evidente da minha dor. Nada mais podia fazer por eles. Mas minha última homenagem eu prestaria de negro, diante deles, lá estaria à hora da execução, a lhe dirigir, com o meu rosto trágico, a última mensagem solidária. Minutos depois, estremeci de medo ao ouvir o primeiro rufar dos tambores. Permaneci de pé no mesmo lugar e troquei com eles o último olhar, quando passaram (eu lhes disse "ainda estou aquil: foi isso o que leram em meus olhos). (p. 53, 54-55)

Ao estar presente junto a eles, mesmo no fim de seus dias, demonstrou sua solidariedade e afeto na fatídica condenação por homicídio e traição aplicada a ambos, pois, qualquer tipo de subversão encerra, antes de tudo, um ato político, o que se transforma numa bela metáfora, traduzida por nós, na necessidade de sermos solidários com essas vidas e corpos, sobretudo, no momento político atua, vivido no Brasil. Diante da realidade brasileira, do país que mais mata LGBT's no mundo, produzindo 347 mortes em 2016, 445 em 2017 e 420 em 20185, as lutas sociais por inclusão dos chamados excluídos, marginalizados e abjetados, apontam para um futuro pleno de retrocessos; entretanto, é sempre pertinente convocarmos a literatura como fonte de inspiração e alimento da alma para a construção da justiça social e de um fazer político que se materialize em redes de solidariedade e intervenção política que possam confrontar a matança da população LGBT. Como a vida, a política e a arte estão todas conectadas, julgamos pertinente para nossa análise, trazer as

\footnotetext{
${ }^{5}$ Segundo a entidade realizadora dos estudos, o Grupo Gay da Bahia (GGB), os dados são subnotificados, já que faltam estatísticas oficiais e comprometimento estatal na construção de dados sérios. Os dados do GGB são alvo de questionamento principalmente por grupos que querem mascarar essa realidade ou relativizar as mortes com $\mathrm{o}$ argumento de que o Brasil é um país que mata muitas pessoas. Na visão construída, neste texto, entendemos as opressões interseccionalizadas, cruzadas entre si e baseadas em uma série de hierarquias simbólico-sociais, nas quais certas situações podem ser agravadas pelo acúmulo de invisibilização social, a exemplo, uma pessoa negra, lésbica e pobre, terá mais condicionante de exclusão do que uma pessoa branca, lésbica e de classe média. Não se trata com isso de hierarquizar a dor, mas sim de entender que ocorrem mecanismos complexos, sofisticados e contextuais do poder.
} 
medidas propostas pelo GGB, no sentido de reversão do quadro atual de violência e discriminação contra homossexuais, bissexuais e transexuais no Brasil, essas são as proposições apresentadas no relatório de crimes contra LGBT’s no Brasil em 2018 realizado pelo referido grupo:

- $\quad$ Educação sexual e de gênero para ensinar jovens e população em geral o respeito aos direitos humanos e cidadania dos LGBT.

- Aprovação de leis afirmativas que garantam a cidadania plena da população LGBT, equiparando a homofobia e transfobia ao crime de racismo.

- Políticas públicas na área da saúde, direitos humanos, educação, que proporcionem igualdade cidadã à comunidade LGBT.

- Exigir que a Polícia e Justiça investiguem e punam com toda severidade os crimes homo/transfóbicos.

Trazemos essas informações e dados que são pertinentes com a nossa perspectiva de elevar a seriedade desse tipo de pesquisa, comprometendo e responsabilizando os mais diversos campos do conhecimento. Deve ser feita a crítica à falta de interesse ou de visibilização para com esses temas e corpos na academia, já que hoje podemos ter a percepção de que muitas teorias e autores consagrados tiveram seus projetos particulares, privados, masculinizados, brancos, e cis-heteronormativos rasurados, (re)lidos e desmascarados, devido à mudança de paradigma, oportunizada, por exemplo, pelas análises pós-estruturalistas, teorias de feministas, feministas negras, estudos culturais, de-coloniais e queer. Isso não quer dizer que devamos jogar a tradição no lixo da história, mas sim (re)lê-la também nas suas entrelinhas, entendendo que a performatividade do gesto científico, em vários momentos, camuflou hipóteses frágeis, ocultando interesses (privados e de classe) da análise, em nome do ideal de uma Ciência, com $\mathrm{C}$ maiúsculo, pura e neutra. Ciência essa que ajudou a solidificar diversos preconceitos e mitos, que estigmatizaram as diversidades de orientações sexuais e de identidades de gênero como crime, aberração, transtorno, patologia e atentado contra a Natureza. 


\title{
PASSION, SUBVERSION AND HISTORICAL RASURE IN THE NOVEL NO PAÍS DAS SOMBRAS (1979) BY AGUINALDO SILVA
}

\begin{abstract}
Our proposal intends to promote rasures to the heteronormative face of the traditional historiography, using, for such objective, the novel No país das sombras (1979), by Aguinaldo Silva. Promoting glances that reflect on the fictional act that presents the (tragic) outcome of a romantic relationship between two "del-rey" soldiers, convicted of conspiracy against Portuguese colonial administration in Pernambuco at 17 th century. We sought to identify how the writer draws parallels about sexual and political repression of the civil-military dictatorship (1964-1988), correlating it to the context of colonial Brazil (16th-17th centuries). In the novel, we analyze how the articulation of the representations of subversion, passion (love and sensuality) and conspiracy (political), are in opposition to the fundamental myths of the hetero-military dictatorship: the feigned morality of the Brazilian family and the harmony of military government. In this way, we put on the stage, in our literary analysis, rasures of those past myths, and the present shadows they project in our actual context. We outline, in the novel, the presence of an agency, which materializes through the subversive act of the character Tália (a courtesan), the articulation between lust and solidarity, the questioning of a certain conception of nature (understood as a set of "Divine" and inflexible rules: a finished product) by preferring nature as "force" (unfinished process, generating possibilities) present in the passion of Antônio Bentes e Oliveira and Pedro Ramalho de Sá.
\end{abstract}

KEYWORDS: Gender; Homoerotism; Solidarity.

\section{REFERÊNCIAS}

BARTHES, Roland. Mitologias. Rio de Janeiro: DIFEL, [1957] 2009.

BUTLER, Judith. Problemas de Gênero: Feminismo e subversão da identidade. Rio de Janeiro: Civilização Brasileira, [1990] 2003.

BONNICI, Thomas. Teoria e crítica pós-colonialistas. In: BONNICI, T.; ZOLIN, L. O. (org.) Teoria da Literatura, abordagens históricas e tendências contemporâneas. Maringá: EDUEM, 2003. p. 258-284.

FOUCAULT, Michel. História da sexualidade I: A vontade de saber. Rio de Janeiro/São Paulo: Paz e Terra, [1976] 2017.

FUKUYAMA, Francis. O fim da historia e o ultimo homem. Rio de Janeiro. Rocco, 1992. 
GASPARI, Elio. Os documentos da censura. Jornal do Brasil, Rio de Janeiro, p.1, 18 jun. 1978.

GINZBURG, Carlo. O fio e os rastros. Verdadeira, falso, fictício. São Paulo: Companhia das Letras, 2007.

. Mitos, emblemas, sinais: Morfologia e história. São Paulo: Companhia das Letras,

1989.

HOLANDA, L. S. B. Da mímesis antiga à imitação dos antigos. Especiaria: Cadernos de Ciências Humanas, Ilhéus v. 11, n.19, p. 133-148, jan./jun. 2008.

HARAWAY, Donna. Saberes localizados: a questão da ciência para o feminismo e o privilégio da perspectiva parcial. Cadernos Pagu, Campinas, SP, n. 5, [1988] 1995, p. 7-41. Disponível em: <https://periodicos.sbu.unicamp.br/ojs/index.php/cadpagu/article/view/17 73/1828>. Acesso em: 25 abr. 2019.

HALL, Stuar. Da diáspora: identidades e mediações culturais. Organização Liv Sovik. 2. Ed. Belo Horizonte: Editora UFMG, [2003] 2013.

GREEN, James Naylor; QUINALHA, Renan Honório. Ditadura e homossexualidades: repressão, resistência e a busca da verdade. São Paulo: EdUFSCar, 2014.

LUKÁCS. Gyorgy, Marxismo e teoria da literatura. 2. ed. São Paulo: Expressão Popular, [1968] 2010.

MARX, Karl. O 18 de brumário de Luís Bonaparte. São Paulo: Boitempo,[1852] 2011. . Manuscritos econômicos filosóficos. São Paulo. Boitempo, [1930] 2004. .; ENGELS, Friedrich. Manifesto Comunista. São Paulo: Boitempo,[1848] 1998.

MALCOLM, Silverman. Protesto e o novo romance brasileiro. 2. ed. Rio de Janeiro: Civilização Brasileira, 2000.

MEIJER, I. C.; PRINS, B. Como os corpos se tornam matéria: entrevista com Judith Butler. Revista Estudos Feministas, Florianópolis, v. 10, n. 1, p. 155-167, Jan. 2002.

MOTT, Luiz. Relações Raciais entre Homossexuais no Brasil Colonial. Revista Brasileira de História, vol., 5, n 10, 1985.

QUINALHA, Renan Honório. Contra a moral e os bons costumes: A política sexual da ditadura brasileira (1964-1988). 2017. Tese (Doutorado em Relações Internacionais) - Instituto de Relações Internacionais, Universidade de São Paulo, São Paulo, 2017.

SCOT'T, Joan W. O movimento \#Me'Too revelou como as mulheres foram educadas a acomodar o poder masculino em vez de o recusar. Jornal Público, Portugal, 2018. Disponível em: https://www.publico.pt/2018/07/01/mundo/entrevista/a-questao-que-hoje- 
nos-desafia-e-como-confrontar-a-crenca-de-que-as-diferencas-sexuais-sao-naturais1836234. Acesso em: 07 dez. 2018.

SILVA, Aguinaldo. No país das sombras. Rio de Janeiro: Civilização Brasileira, 1979.

TREVISAN, João Silvério. Devassos no paraíso: a homossexualidade no Brasil, da colônia à atualidade. 4. Ed. Rio de Janeiro: Objetiva, 2018.

VAINFAS, Ronaldo. Trópico dos pecados: Moral, Sexualidade e Inquisição no Brasil. Rio de Janeiro: Civilização Brasileira, 2010.

VIEIRA, Fernanda D. A caça aos homossexuais e às travestis na ditadura militar. Pragmatismo Político (site), ago. 2015. Disponível em: https://www.pragmatismopoli-

tico.com.br/2015/04/a-caca-aos-homossexuais-e-travestis-na-ditadura-militar.html. Data de acesso: 02/02/2019.

Recebido em: 01/06/2019.

Aprovado em: 19/07/2019. 